\title{
PADRINS I FILLOLS \\ A LA CATALUNYA \\ ALTOMEDIEVAL. APORTACIÓ \\ A L'ESTUDI DEL PARENTIU \\ ARTIFICIAL
}

Antoni M. Udina Abelló

Els darrers anys, l'estudi de la societat feudal a l'Occident europeu ha obert noves perspectives fonamentades en la utilització de disciplines científiques que fins fa ben poc temps eren emprades rarament en l'elaboració de treballs històrics, com ara la sociologia, l'estadística o l'antropologia cultural. Ja Lucien Febvre ho veia amb clarividència fa més de trenta anys en dir: «Negociar perpetuamente nuevas alianzas entre disciplinas próximas o lejanas, concentrar en haces sobre un mismo tema la luz de varias ciencias heterogéneas: ésta es la tarea primordial, la más urgente y la más fecunda, sin duda, en las que se imponen una historia que se impacienta ante las fronteras y los compartimientos estancos»1.

En aquesta línia i en to profetic, podríem dir, Marc Bloch elaborà la seva obra fonamental sobre La société féodale, pionera in-

1 Lucien Febvre, Combates por la historia, Barcelona 1970, traducció de l'original francès de 1953 , p. 30. 
discutible de la historiografia moderna sobre el tema ${ }^{2}$. No és ara el moment de fer una valoració historiogràfica del feudalisme. Ho ha fet ja Alain Guerreau en una obra polèmica i discutida ${ }^{3}$. Precisament en aquest llibre, un cop s'ha fet un recorregut per les diverses teories sobre el feudalisme, l'autor proposa noves vies d'investigació per accedir a la problemàtica feudal, i entre aquestes es planteja la necessitat d'escatir la importància del parentiu artificial en les relacions de la societat medieval i específicament la feudal; Guerreau afirma sobre aquest punt: «La estructura de parentesco estaba subordinada a la estructura eclesiástica» ${ }^{4}$. Respecte al parentiu artificial en l'esmentada obra es formulen una sèrie d'hipòtesis que veurem més endavant si són verificables després de l'anàlisi documental que hem dut a terme 5 .

En una encertada mise au point dels estudis sobre qüestions antropològiques aplicades a les societats medievals, Anita GuerreauJalabert ens parla de la manipulació operada per l'Església sobre el parentiu a l'època medieval manifestada pel pseudo-parentiu, del qual són exemples clars l'agermanament, l'adopció i el padrinatge ${ }^{6}$.

L'estudi de les estructures de parentiu i llur influència en la formació i consolidació del feudalisme a Catalunya ha estat iniciat per J. Enrique Ruiz Doménec i alguns dels seus deixebles. Les primeres conclusions a què han arribat aquests treballs remarquen la importància extraordinària de la teoria de l'aliança en la vertebració de la societat feudal, per mitjà del matrimoni entre cosins creuats, que permet l'accés social dels homes mitjançant el lliurament de dones d'un llinatge superior?.

2 Marc Bloch, La société féodale, 2 vols. Paris 19492.

${ }^{3}$ El feudalismo, un horizonte teórico, Barcelona 1984.

4 A. Guerreau, obra citada a la nota 3, p. 214.

5 Ens referim essencialment a la possiblitat que el fillol suplís el fill en la successió de persones no casades o de matrimonis estèrils.

6 «Sur les structures de parenté dans l'Europe médievale», Annales, Économie. Sociétés. Civilisations, nov.-déc. 1971, pp. 1028-1049, en especial p. 1035.

7 Veg., en concret, J.E. Rum DoMÉNEC, «Système de parenté et théorie de l'alliance dans la societé catalane (env. 1000-env. 1240)», Revue Historique 532. 1979, pp. 305-326; Blanca GARI, El linaje de los Castellvell en los siglos XI y XII. Un análisis prosopográfico de sus estructuras familiares y su organización social. 
Caldrà seguir aquest camí, que veiem com a interessant i molt prometedor, verificant en estudis successius aquesta hipòtesi de treball que plantejà i demostrà en bona part, per a altres zones de l'Occident europeu, Duby ${ }^{8}$.

Volem nosaltres, en aquestes ratlles, aportar modestament unes dades sobre un altre aspecte antropològic encara per estudiar a casa nostra: el parentiu artificial, anomenat també pseudo-parentiu, al qual en el pla teòric s'han referit les obres abans esmentades ${ }^{9}$. I dins d'aquesta mena de parentiu ens centrarem en 1'estudi de la relació que s'estableix mitjançant el padrinatge, institució de la qual tenim notícies ja en època visigòtica, concretament en obres de sant Isidor i sant Ildefons ${ }^{10}$, i que és objecte de regulació l'any 578 en el Concili d'Auxerre, on és prohibit als monjos ésser padrins, i en la compilació de Justinià, en què es prohibeix el matrimoni entre padrí $i$ fillol"1.

Malgrat que els segles X i XI, període en el qual centrem el nostre treball, les notícies sobre el padrinatge són relativament escadusseres $\mathrm{i}$ incompletes, per mitjà de l'estudi global de les mencions de filioli i baptizati que trobem als testaments, creiem que podem intentar un primer apropament a la qüestió, mirant d'aprofitar al màxim possible les escasses dades obtingudes, que resumim als dos quadres de l'apèndix d'aquest treball.

Pierre Bonnassie, un dels millors especialistes sobre la Catalunya feudal, no s'ha adonat de la importància que poden tenir les qüestions relacionades amb el parentiu per consanguinitat per aliança a què ens hem referit abans. Pel que fa al parentiu artificial, quan tracta de l'estructura del grup familiar es refereix als «llegats

tesis doctoral inèdita, Bellaterra, Universitat Autònoma de Barcelona 1983; María PONT, Las estructuras familiares catalanas en los siglos XI-XII, introducción a su estudio, tesina de llicenciatura inèdita, Bellaterra, Universitat Autònoma de Barcelona 1976.

8 Georges DUBY, «Lignage, noblesse et chevalerie au XII siècle dans la region macconnaisse. Une revision», Annales ESC 127, 1972, pp. 803-823.

9 Veg, notes 3 i 5.

10 Migne, Parrologia Latina, vol. 83 cols. 815,820 i vol. 96 cols. 34, 113-114.

11 CABROL, Dictionnaire d' archéologie chrétienne et liturgie, Paris 1938, vol. 13, 2 ème part, col. 2238 i 2239. 
destinats a filiatos o baptizatos», que considera més freqüents als testaments de dones i que considera que, en la majoria de casos, son simples fillols, per més que en algun cas assenyali que es pot tractar de fills adoptius ${ }^{12}$.

Aquí se'ns planteja la primera dificultat: la qüestió terminològica, problema del qual ja es feia ressó Marc Bloch els anys quaran$\mathrm{ta}^{13}$, i que més recentment ha preocupat Georges Duby en aprofundir en l'anàlisi de la societat feudal, quan diu: «Le vocabulaire est bien sans doute le document le plus riche dont dispose l'historien de la psychologie sociale, le plus riche, mais aussi le plus difficile à exploiter, car les mots sont des enveloppes dont le contenu n'est pas le même dans les différents milieux sociaux, et se modifie d'autre part avec le temps»14.

Així, en els documents - bàsicament testaments i les seves recepcions sagramentals - que hem examinat en el nostre cas, observem diversos mots que ens suggereixen una relació de pseudo-parentiu evident, com per exemple: filioli, baptizati, filiati, nutriti, nutricati. No sabem fins a quin punt les paraules filioli i baptizati poden considerar-se com a sinònimes i designen els fillols; per això en farem l'estudi separadament. Quan es parla de filiati, ens inclinem per creure que bé es pot tractar d'afillats per adopció, institució que no sembla que conegués a Catalunya un descabdellament tan important com en altres zones de la península ibèrica ${ }^{15}$. El cas dels nutriti o nutricati és més clar: es tractaria de cavallers que s'educaven - es nodrien - fora de la seva llar natural — la dels pares-. sovint a casa del seu oncle matern ${ }^{16}$.

En una mostra documental investigada sobre un total de 535 testaments hem trobat 41 mencions de filioli (veg. quadre I), a les

12 Pierre Bonnassie, Catalunya mil anys enrera I, p. 237, Barcelona 1979.

13 Apologia della Storia. Torino 1969, traducció de l'original francès de 1949. p. 137.

14 La feodalité? Une mentalité médievale?n, Hommes et structures du Moyen Âge, Paris 1973.

15 Abilio BARBero y Marcelo Vigil., La formación del feudalismo en la Peninsula Ibérica, Barcelona 1978, pp. 380-394.

16 RUIZ DOMf́NEC, obra citada a la nota 7, p. 317. 
quals podem afegir una cita de patrinus i una altra de filiolus que rep una donació ${ }^{17} ; 15$ de baptizati (veg. quadre II); 8 de nutriti i 2 de filiati ${ }^{18}$.

Cal tenir en compte que les quaranta-una mencions de fillols es fan en vint-i-nou documents; és clar per a nosaltres que, del silenci de la gran majoria de testaments sobre els fillols, no en podem concloure la seva inexistència; en tot cas en podem fer una primera valoració en el sentit que les relacions derivades d'aquesta mena de parentiu no sembla que revestissin una importància gaire gran, per bé que seria agosarat extreure'n conclusions taxatives. Volem dir amb tot això que és evident que el nombre de fillols que realment devien existir és molt més gran que el trobat en els documents analitzats, però, com es lògic, hem de limitar el nostre estudi a la realitat - encara que sigui parcial- que ens reflecteixen els documents. D'altra banda, els esments de nutriti sovintegen en altres tipus documentals, les convinences per exemple, que no hem treballat, ja que com hem dit volem limitar-nos en aquest treball a l'anàlisi de les relacions derivades del padrinatge.

A més de les breus al-lusions de Bonnassie esmentades abans, només tenim notícia d'un treball que es refereixi a aquest tema, l'autor del qual és el destinatari d'aquesta miscel-lània, de la qual aquest nostre treball forma part ${ }^{19}$. Frederic Udina recull una menció de filiolaticum, institució a la qual ens referirem més endavant.

Com ja hem assenyalat, tractarem per separat les dades obtingudes de les citacions de filioli i de baptizati, malgrat que creiem que expressen conceptes molt propers, si no idèntics.

17 Guilabert Ramon parla d'una vinya que li vingué del seu padrí en el testament de 5 de març de 1096, ACB LA IV núm. 118. La donació a ACV cal. 6 perg. 1053 (any 1066). Mencions de filioli en sentit figurat de fills, en el testament d'Ermangol, bisbe d'Urgell, VILLANUEVA, Viage literario... X doc. 29.

18 Mencions de nutriti a ACB pergs. 1-1-185 (1054): ACA C perg. 224 de Ramon Berenguer I (1058); ACV Ep. II perg. 59 (1058); ACA C perg. 413 de Ramon Berenguer I (1069); VILLANUEVA, op. cit. XII doc. 28 (1064); CSC ed, RIUS, II núm. 678 (1073) i ACB LA II núm. 40 (1084), on trobem dues mencions. Mencions de Filiati a CSC ed. RIUS II, 377 (1002) i ACU LDEU I núm. 394 (1029).

19 Federico UDINA MARTORELL, «El fillolarge, institución jurídico-familiars, Anuario de Historia del derecho español, 1959, pp. 541-544. 
Pel que fa a les mencions de fillols (filioli) en testaments o publicacions sagramentals, els testadors dels quals en són padrins, una primera anàlisi quantitativa ens dóna els resultats següents atenent a la seva cronologia:

\begin{tabular}{rcc}
\hline Període & Documents analitzats & Mencions de fillols \\
\hline $840-1000$ & 57 & 2 \\
$1001-1020$ & 63 & 2 \\
$1021-1040$ & 85 & 7 \\
$1041-1060$ & 76 & 10 \\
$1061-1080$ & 105 & 13 \\
$1081-1100$ & 149 & 7 \\
\hline TOTAL & 535 & 41 \\
\hline
\end{tabular}

Malgrat que encara ens manca verificar prop d'un centenar més de testaments del segle XI, podem veure una evolució del nombre de fillols de caire positiu que ateny el seu punt màxim en el període 1053-1069, en el qual comptabilitzem el $40 \%$ de citacions de fillols. Cal tenir en compte que només hem comptat els fillols en el testament quan, a més, se'ns ha conservat la publicació sagramental, i que en els casos que el document no especifica el nombre de fillols i utilitza el plural, n'hem considerats dos.

¿Qui són els padrins, és a dir, els testadors les deixes dels quals van adreçades en part als fillols? Cinc dones $i$ vint-i-quatre homes, més una dona que fa una donació d'un alou situat a Manlleu per al seu fillol Amau ${ }^{20}$, resulten de la distribució per sexes; xifres que es corresponen quasi amb exactitud amb la proporció que hi ha entre testadors i testadores en el total de testaments estudiats: $18 \%$ de dones i $82 \%$ d'hom:es, la qual cosa, lluny de sorprendre'ns, ratifica la creença de l'existència de padrí i padrina, per bé que no coneixem documentat cap cas en què constin tots dos padrins d'un mateix fillol.

$20 \mathrm{ACV}$ cal. 6 perg. 1053 (1066). 
Dels vint-i-quatre padrins homes, tretze són eclesiàstics: un bisbe, un monjo, cinc canonges i sis preveres ${ }^{21}$ i onze, laics: en aquest cas la proporció és força diferent ja que en el total de testadors que són homes, en els testaments investigats hi ha un $66 \%$ de laics, mentre que en el nombre de padrins laics representa poc més del $45 \%$ del total. Això ens pot indicar, doncs, que el més freqüent era que els padrins fossin clergues, sempre segons els documents estudiats. D'altra banda, cal tenir present que en alguns casos els testadors tenen més d'un fillol (docs. 6, 7, 9, 12, 13, 14, 18, 20, 21, 22 , 23,26 i 29 del quadre I), la qual cosa ens fa pensar que molts testadors - tant homes com dones i religiosos com laics-, malgrat no fer deixes testamentàries a fillols, eren padrins; això ens fa una idea de la dificultat de l'estudi que emprenem.

Pel que fa a la condició social dels padrins laics, cal remarcar el fet que no figuren com a tals els membres de l'alta noblesa - considerem com a tals els titulars de castells, sigui com a propietaris, sigui com a feudataris dels comtes -; ¿vol dir això que realment els nobles no tenien fillols? Creiem que més aviat el que passa és que en la successió d'aquest grans nobles, els possibles fillols resten preterits en favor dels parents consanguinis i fins i tot de monestirs i esglésies. Set dels testadors laics podem considerar-los cavallers, encara que explícitament només en un cas consta amb el nom de miles (doc. 24). En altres casos també els considerem com a tals (docs. 4, 17, 20 i 22), i en alguns, amb certes reserves (docs. $18 \mathrm{i}$ 19) (ens referim sempre als quadres de l'apèndix). Les cinc dones de les quals consta l'existència de fillols, creiem també que pertanyien a la petita noblesa (docs. 5, 6, 23, 26 i 28); tres dels testadors padrins podrien formar part dels cives (docs. 10, 11 i 21) i, finalment, un podria ser un pagès petit propietari (doc. 25). Ací la proporció és semblant a la que hi ha en el total de testadors. Quant als baptizati, reben deixes de: tres preveres (docs. C, E, H), un monjo (doc. F), un home de negocis (doc. B) i quatre persones més de la petita noblesa (docs. A, D, G i I).

21 Bisbe, doc. apèndix, 2. Canonges, docs. 12, 13, 14, 15, 16. Monjo, doc. 3. Preveres, docs. 1, 7, 8, 9, 27, 29. 
Qui són filioli i baptizati? La identificació dels filioli es fa molt sovint a través de la filiació, sense citar, en molts casos, el nom: afilius Eldemar», «filius Igila», «filius Elliardis», «filia Isarni Sunier» (docs. 7, 8, 15 i 19, respectivament); en d'altres es cita el nom (docs. 2, 3, 4, 5, 13, 14, 24, 25..) o bé nom i cognom (docs. 11, 12, $14,17,19)$. Finalment, en alguns es fa senzillament al-lusió genèrica de filioli, sense especificar-ne ni noms ni filiació (docs. 6, 18, 21,23 ). En el cas dels baptizati, s'acostuma a citar-los pel nom (vegeu quadre II). Guifre Sendret es refereix genèricament a baptizati i filioli de manera conjunta (doc. 19).

Quina relació hi ha entre padrins i fillols? Generalment, sembla que és l'amistat del padrí amb els pares del fillol la raó del padrinatge, com es pot veure a les citacions dels filioli per la filiació. En alguns casos, veiem com coincideixen el parentiu de consanguinitat amb l'artificial, derivat de la relació padrí-fillol: el cas d'Erúcia, qualificada de neboda i fillola del testador Amalric (doc. 25), o bé altres casos en què podem deduir la condició de nebots dels filioli; així, per exemple, en la deixa que el prevere Folc fa d'un camp al seu germà Oliba i al seu fillol Mir, que suposem fill d'Oliba i, per tant, nebot del testador (doc. 27). Una altra mena de motiu per al padrinatge deriva de la mateixa relació feudal, com podem veure per partida doble en el testament de Gelmir (doc. 20), en el qual es diu d'un dels fillols, Arnau, «que abent nutriton, la qual cosa representa un reforç de la relació de parentiu espiritual en el sentit que ja hem apuntat en parlar dels nutriti; també trobem una deixa en favor de la fillola del testador, filla del senyor Guillem Bernat, els quals figuren com a hereus d'un alou deixat en usdefruit a l'esposa de Gelmir: és evident que en aquest cas hi té més pes la condició dominical que no la del padrinatge, però és significatiu que el parentiu espiritual es basi en la relació feudal, un altre tipus, al cap i a la fi, de parentiu artificial.

Entre les atribucions que tradicionalment s' han considerat reservades al padrí destaca el fet d'escollir el nom dels fillols, i molt sovint posar-li el seu propi nom. En l'època investigada no hem trobat cap cas en què coincideixen el nom del testador amb el del fillol - ni filioli, ni baptizati-, encara que és veritat que en setze dels 
cinquanta casos no hi figura el nom del fillol, sinó la seva filiació o la simple denominació genèrica (vegeu quadres $\mathrm{I}$ i III). Una altra opinió generalitzada és que sovint el padrí era l'avi: hem trobat un cas en què es fa referència a una terra que procedeix de l'avi, qualificat de patrinus ${ }^{22}$. El fet de no trobar més mencions sobre això no crec que pugui ser prou per negar el fet, primerament perquè en alguns testaments hi ha deixes a néts qualificats com a tals que podrien ser també fillols - no hi ha dubte que el parentiu per consanguinitat era més important que l'artificial-; i en segon lloc, que en la gran majoria de casos els beneficiaris testamentaris són els fills, no pas els néts. En tot cas, cal fer constar el que ens diuen els documents.

Passem ara a l'anàlisi de les disposicions testamentàries referides a filioli i baptizati. La seva quantificació i qualificació ens pot aclarir un xic més el sentit de la seva relació. Normalment, es tracta de disposicions patrimonials sobre béns arrels o mobles, com veurem tot seguit. Cal abans, però, fer esment d'un testament que representa un cas únic, excepcional si es vol, però ben significatiu: és el de Mir Queruci, que creiem canonge de la catedral barcelonina (doc. 13), el qual formula una sèrie de disposicions molt detallades respecte al seu fillol Joan. A més de contenir deixes de béns diversos, regula amb força detall tota una altra munió d'aspectes ben il-lustratius, com podem veure en el fragment del testament que reproduïm a continuació:

Et concessit ad lohannem, filiolum suum, ipsos suos domos ubi habitabat cum solos et supperpositos et ortulum unum, quos emit de Poncii Guitardi et est iuxta casulam predicte canonice, et vineas modiatas IIII qu qui fuerunt de Mironi Manuferica, et alias duas modiatas vinee, quos emit de Blancha et de filiis filiabusque suis. Hoc ordine concessit ei hec supradicta monia ut Mironis Guilelmi et Mironis Gultredi teneant et faciant eum erudire litteris et tribuant ei omnia que illi necesse fuerit usquequo perveniat ad XV annos; postquam vero transierint $X V$ annos, si supradictus Iohannes vivus fuerit teneat et possideat in diebus suis, et tonnas II et cupus I. quos emit de Seniofredus Petrus et cavags II et podadores II et parilios

22 F. UDINA, obra citada a la nota 18, p. 542. 
II de portadores et cubello uno folador et torcular cum omnia sua utensilia. Hec omnia suprascripta teneat lohannes predictus omnibus diebus vite sue solide ac de libere exceptus supradictos XV annos. Post obitum vero suum remaneat ad iamdicta canonica. Et rogavit domini sui episcopi et omnes canonici ego Miro servulus vester, ut predicto Iohanni impreciatis ei omnia qui ille necesse fuerit et in vestro consortio retineatis quia vos sctitis quomodo ego eum adquisivi...

A més de tractar-se de la deixa més abundant que rep un fillol que hem localitzat, és remarcable la minuciosa regulació sobre l'educació del fillol, encomanada a uns altres canonges, i que pretén tendir a la formació de l'infant cap a la carrera eclesiàstica: la destinació final de tots els béns a la catedral barcelonina un cop mort Joan ens en sembla una prova evident. En aquest testament trobem altres deixes a germans del testador consistents en cases, terres, esglésies, unces d'or; però una de les més importants és la referida al fillol Joan, que acabem de reproduir; al costat de Joan veiem un altre fillol «filium Gaucberti», a qui lega el testador un mancús. Volem subratllar amb això que el tal fillol Joan adquireix un paper molt important en l'herència de Mir Queruci, gairebé com si es tractés d'un fill. Recordem ací el que en diu Guerreau: «La elección de un ahijado era la sustitución simple y sacralizada de una adopción " ${ }^{23}$. Una altra mena de disposicions d'aquest mateix testament s'adrecen a econmanar el fillol al bisbe $i$ als canonges de la catedral d'una manera genèrica. L'encomanació in baiolia del fillol la trobem també en el testament de Guitard Ananies respecte al seu «baptizato et nutrito Bernardo», que deixa a cura de Mir Guadall i Mir Guillem (doc. B).

El que és, però, més corrent, és disposar deixes de béns en favor dels fillols, com podem veure en els quadres que clouen el present treball i que ací resumirem. També en actes inter vivos; si bé com una cosa excepcional, tenim documentades algunes al-lusions a padrins i fillols: la donació d'un alou que és a Santa Maria de Manlleu fet per Riquildis, l'any 1066, al seu fillol Arnau, fill del prevere Ra-

23 Obra citada a la nota 3, p. 214. 
mon, que és qui el tindrà mentre visqui ${ }^{24}$, n'és un exemple. Un altre cas és el d'Ató, que fa al seu fill Guifre una venda d'una terra que es diu procedent «per filiolaticum quod mihi fecit patrino suo nomine condam Auderii, avius suus» ${ }^{25}$. Frederic Udina parla de la possibilitat del fillolatge com a institució que no arribà a quallar: en un testament del 1031, un tal Sindered deixa diversos mobles «ad filia Oliba per filiolatico». Fixem-nos, però, que no es tracta d'una fillola, sinó de la filla ${ }^{26}$. D'altra banda, si, quan més sovintegen les mencions de fillols, des del 1050, no surt mai el terme filiolaticum, hem de pensar que la institució no arribà, com a tal, a arrelar.

En la majoria de deixes a fillols que figuren en els testaments trobem béns mobles; en primer lloc, de numerari: uncias, mancusos, sous i argencis (docs. 12, 13, 14, 21, 22, 23, 26 i B), en quantitats que oscil-len d'un a cinc, i dels quals sovint es veuen beneficiades també moltes altres persones (docs. 12, 13, 21 i 23). Dins del context global, aquestes deixes de numerari representen una part molt petita de l'herència. Béns relativament freqüents en deixes que reben els fillols són ordi i vi, essencials per a l'alimentació (docs. $7,9,11,17,18,22, \mathrm{C}$, D i F), si bé no de manera exclusiva, ja que també en són beneficiaris persones físiques sense cap parentiu amb el testador, i persones jurídiques (docs. 7, 11, 17 i B). Animals diversos formen part d'algunes de les deixes que comentem: ovelles, porcs, vaques, oques, eugues i pollins (docs. 3, 4, 5, 6, 10, 14, 19, 28,29, B, C, D i H). I finalment - dins dels béns mobles-cal assenyalar els atuells i objectes de la casa (docs. 13, C, D i H).

Els béns arrels, encara que no tan freqüents, també son objecte de deixes del patrimoni dels testador als fillols, ja es tracti d'un alou (docs. 1 i 20), de vinyes (docs. 2, 3, 13, 25, A, E i G), de cases i horts (docs. 13 i E), de camps i terres (docs. 8, 20 i 27), o de sagreres (doc. 29). En alguns casos, aquests béns immobles són deixats en precari o en usdefruit, i s'assenyala la destinació que han de tenir un cop morts els primers beneficiaris - els fillols - : així, el prevere

24 Document citat a la nota 19.

25 F. UDINA, obra citada a la nota 18, p. 542.

26 ACA C. perg. 93 de Ramon Berenguer I. 
Folc disposa la deixa d'un camp al seu germà Oliba i Mir, fillol del testador i fill del germà, amb obligació que donin una quarta part de la collita a Sant Pere de Vic, on anirà a parar l'esmentat camp en morir els dits Oliba i Mir (doc. 27); la casa i hort deixats a Ermessenda baptizata de Bonuci Vivas, seran, en morir ella, per a un nebot del testador (doc. E); Baró Ramon disposa que la mojada de vinya llegada a Ruzrig, el seu baptizatus, sigui, en morir, per als seus fills mascles, i morts ells, per a Sant Cugat del Vallès (doc. G).

Un darrer interrogant cal fer-se davant l'anàlisi de la documentació estudiada relativa als fillols. ¿Fins a quin punt els fillols prenen el lloc dels fills en la successió testada de persones que no en tenen, sigui per esterilitat, per mortaldat infantil o per la condició clerical? Ens hem referit fa ben poc al cas de Mir Queruci respecte al seu fillol Joan (doc, 13), que, malgrat tot, es presenta com a excepcional. Dels trenta-vuit documents en què hem trobat citats $f i$ lioli o baptizati —en alguns, més d'un, com ja s'ha vist-n'hi ha vuit en què els principals beneficiaris - hereus en un sentit vulgar, no tècnic-són els fills del testador (docs, 11, 17, 18, 26, 28, A, D i G); en dos testaments d'aquests vuit, figuren deixes d'immobles a baptizati (docs. A i G), mentre que la resta de fillols rep deixes de béns mobles (vegeu quadres I i II), i queden reservats per als fills els béns immobles, cosa que segueix la norma pel que fa a la destinació d'un i altre tipus de béns, com nosaltres mateixos hem demostrat per a la primera època27. L'únic cas dels 38 documents citats en el qual no figura com a beneficiari de les deixes cap parent del testador és el testament de Sanç (doc. 10). Podem deduir d'això que no en té; el document ens parla de la seva esposa ja morta, i malgrat això, la fillola no rep més que una ovella, mentre que hi ha persones, de les quals no consta la seva relació amb el testador - hem de suposar-les amics-, que reben deixes semblants i fins i tot més importants. Així, un tal Bernat rep una peça de terra; Amalric, una llança; el bisbe, mancusos, etc.

En conclusió, a la Catalunya del segle XI, no sembla que el parentiu artificial creat pel bateig $i$ altres sacraments entre padrins i fi-

27 Antoni M. UdINA ABELLO, La successió testada a la Catalunya altomedieval. Barcelona 1984, pp. 107-113. 
llols tingui un paper destacat en les relacions socials de l'època de formació i consolidació del feudalisme català. En efecte, d'una banda, la menció explícita de filioli i baptizati és escassa, i de l'altra, el paper que hi tenen com a beneficiaris és també de segon ordre. Caldrà, en tot cas, veure si durant els segles posteriors creix la seva importància - fenomen lligat potser a la recepció del dret romanocanònic-, ja que sabem que el segle XIV el padrí obsequia el fillol amb una moneda d'or ${ }^{28}$.

\section{LLISTA D'ABREVIATURES}

$\begin{array}{ll}\text { ACA } & =\text { Arxiu de la Corona d'Aragó } \\ \text { C } & =\text { Cancelleria } \\ \text { M } & =\text { Monacals } \\ \text { ACB } & =\text { Arxiu Capitular de Barcelona. } \\ \text { LA } & =\text { Libri Antiquitatum } \\ \text { ACU } & =\text { Arxiu Capitular de la Seu d'Urgell } \\ \text { LDEU } & =\text { Liber dotaliorum ecclesiæ Urgellensis. } \\ \text { ACV } & =\text { Arxiu Capitular de Vic } \\ \text { cal. } & =\text { calaix } \\ \text { Ep. } & \text { Episcopologi } \\ \text {.dot. } & =\text { Liber dotationum antiquarum } \\ \text { ADB } & =\text { Arxiu Diocesà de Barcelona } \\ \text { ADM } & =\text { Archivo del Duque de Medinaceli, Sevilla } \\ \text { BC } & =\text { Biblioteca de Catalunya } \\ \text { BNP } & =\text { Bibliothèque Nationale de Paris } \\ \text { CSC } & =\text { Cartulari de Sant Cugat. } \\ \text { carp. } & =\text { carpeta }\end{array}$

28 Informació subministrada per Rafael Conde, que li agraeixo de tot cor. 


$$
\begin{array}{ll}
\text { ed. } & =\text { edició } \\
\text { doc. } & =\text { document } \\
\text { f. } & =\text { foli } \\
\text { perg. } & =\text { pergamí }
\end{array}
$$

MONTSALVATGE = Francisco MONTSALVATGE, Noticias históricas sobre el condado de Besalú. Olot 1889-1919.

RIUS, José. Cartulario de San Cugat. Barcelona. 1945-47

VILLANUEVA = VILLANUEVA, Viatge literario a las Iglesias de España . Valencia-Madrid 1803-1852.

\section{APÈNDIX}

Oferim a continuació, sistematitzades en dos quadres, les dades obtingudes de l'anàlisi dels documents objecte d'aquest estudi, pel que fa a la data i signatura del document, testadors, fillols i béns deixats a ells en testament. 


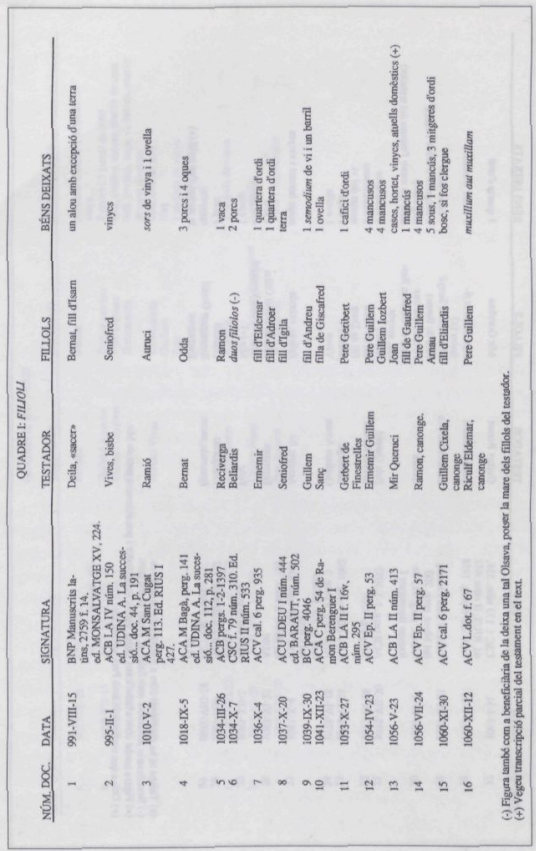




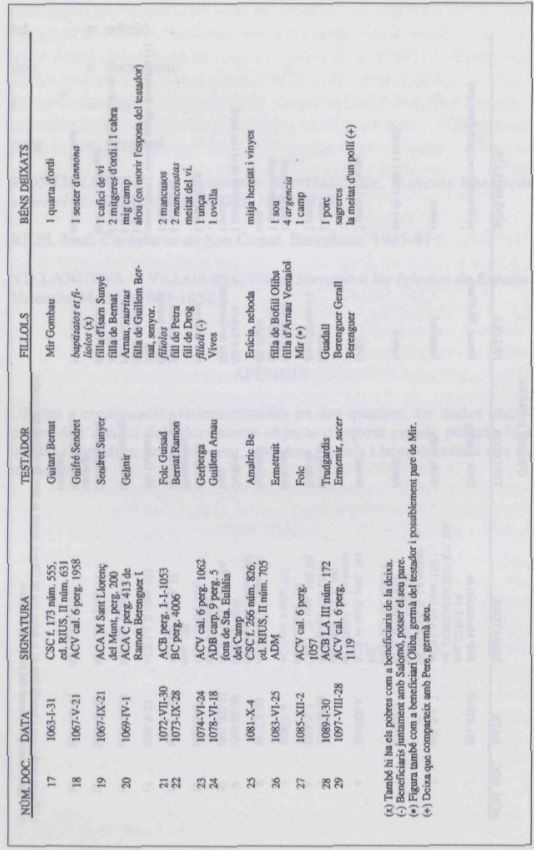




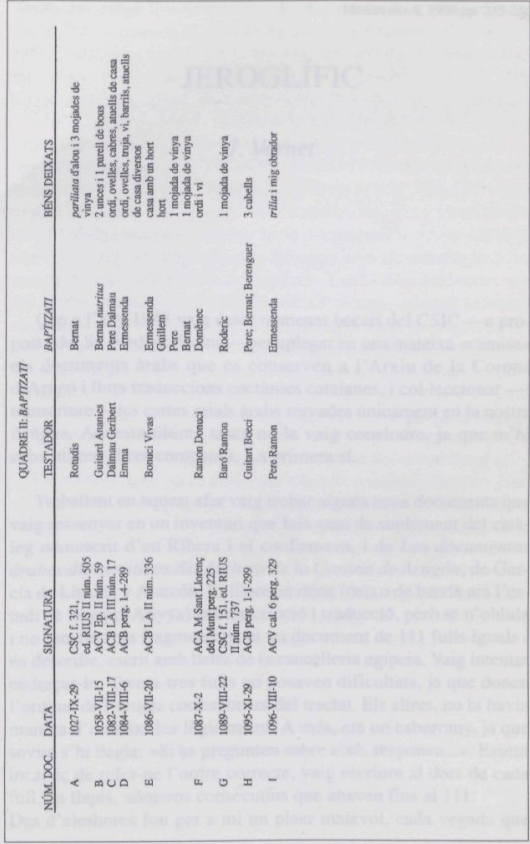

